\title{
Educação Ambiental: Retrocessos e contradições na Base Nacional Comum Curricular
}

\section{Environmental Education: Retrocesses and contradictions on the common curricular national basis}

\author{
Ronualdo Marques ${ }^{1}$ \\ Jerry Adriano Raimundo² \\ Claudia Regina Xavier ${ }^{3}$
}

\section{Resumo}

No presente estudo é analisado como a Educação Ambiental se apresenta na ultima versão homologada da Base Nacional Curricular Comum e a partir da sua manifestação expor elementos de contradições e retrocessos no campo da temática transversal uma vez que, possui uma construção histórica que

1 Mestre em Ensino de Ciências no Programa de Mestrado em Educação Científica e Tecnológica pela Universidade Universidade Tecnológica Federal do Paraná (PPGFECT-UTFPR); especialização em Educação Especial pela Faculdades Integradas do Vale do Ivaí (UNIVALE); especialização em Educação e Gestão Ambiental pela Faculdades Integradas do Vale do Ivaí (UNIVALE); especialização em Gestão Pública Municipal pela UTFPR - Universidade Tecnológica Federal do Paraná (UTFPR); especialização em Filosofia Contemporânea pela Faculdade de Administração, Ciências, Educação e Letras (FACEL). Graduando em Pedagogia no Centro Universitário Internacional (UNINTER). Graduação em CIÊNCIAS BIOLÓGICAS pela Universidade Estadual do Centro-Oeste (UNICENTRO).

2 Mestre em educação na Universidade Federal do Paraná (UFPR-2017). Especialista em Filosofia Contemporânea (FACEL-2013); Especialista em Psicopedagogia Institucional e Clínica (ESAP-2011); Licenciado em PEDAGOGIA? (UEM-2010); Licenciado em Normal Superior (UEM-2009); e, Bacharel em Teologia (SPR-2003). Docente em anos iniciais, ciclo II, na Prefeitura Municipal de Curitiba (2012)

${ }^{3}$ Profa. Dra. no Programa de Mestrado de Formação Científica, Educacional e Tecnológica - FCET/UTFPR. Possui graduação em Licenciatura e Bacharelado em Química pela Universidade Federal do Paraná (1996) e mestrado em Química pela Universidade Federal do Paraná (1998). Participou em Treinamento Avançado em Instrumentos de Gestão Ambiental em Hamburgo- Alemanha (2001) e posteriormente se titulou doutora em Ciências Ambientais pela Universidade de Concepción- Chile (2006). Atualmente é Professora Titular da Universidade Tecnológica Federal do Paraná- UTFPR.

Interfaces da Educ., Paranaíba, v.10, n.28, p.445 à 467, 2019

ISSN 2177-7691

Recebido em setembro de 2019 e aprovado em outubro de 2019 
fundamenta a sua efetividade no currículo escolar. Nesse sentido, tivemos como objetivo analisar sob a perspectiva do método da complexidade qual o espaço dedicado a Educação Ambiental no currículo escolar e apontar elementos para enfrentar as contrarreformas da educação brasileira. Foi realizada uma pesquisa qualitativa de característica exploratória e examinadas pela Análise Textual Discursiva. Observou-se pelos resultados apresentados que a Educação Ambiental é obscurecida sendo tratada no currículo escolar prevalecendo uma abordagem tradicional, naturalista e conservadora. Na contramão dessa intencionalidade, torna-se cada vez mais emergente consolidar no currículo escolar a Educação Ambiental na perspectiva crítica, emancipatória e transformadora, a qual busca a formação da cidadania a partir das problematização em que se consideram os aspectos sociais, éticos, econômicos, políticos, tecnológicos e culturais.

Palavras-chave: Educação Ambiental. BNCC. Currículo escolar. Educação Básica. Temática transversal.

\section{Abstract}

This study analyzes how Environmental Education presents itself in the latest approved version of the Common National Curricular Base and from its manifestation expose elements of contradictions and setbacks in the field of cross-cutting thematic since it has a historical construction that underlies its effectiveness. in the school curriculum. In this sense, we aimed to analyze from the perspective of the complexity method the space dedicated to Environmental Education in the school curriculum and to point out elements to face the counter-reforms of Brazilian education. A qualitative exploratory research was performed and examined by the Discursive Textual Analysis. It was observed by the results presented that the Environmental Education is obscured being treated in the school curriculum prevailing a traditional, naturalistic and conservative approach. Against this intentionality, it is becoming increasingly emergent to consolidate 
environmental education in the school curriculum in a critical, emancipatory and transformative perspective, which seeks the formation of citizenship from the problematization in which the social, ethical, economic, social and economic aspects are considered political, technological and cultural.

Keywords: Environmental Education. BNCC. School curriculum. Basic Education. Cross Thematic.

\section{Prolegômenos}

A Educação Ambiental vem sendo sistematicamente suprimida de documentos norteadores da Educação no Brasil. Contudo é importante ressaltar que é um campo de pesquisa em expansão no Brasil e que a Educação Ambiental surgiu da necessidade de uma mudança de paradigma que envolve valores sociais, filosóficos, econômicos, éticos, ideológicos e científicos, adotados pela nossa sociedade.

Contudo, vemos como sinal de alerta o esvaziamento da Educação Ambiental nos documentos que orientam a Educação no Brasil, pois percebemos os avanços alcançados nas ultimas décadas na consolidação de Políticas públicas na área ambiental na qual a escola é corresponsável pela promoção dessas mudanças, pois tem como premissa fazer com que os envolvidos desenvolvam as suas potencialidades e adote posturas pessoais, comportamentais e socialmente construídas, colaborando para a construção de uma sociedade igualitária e ambientalmente justa, em um ambiente saudável.

Neste sentido apresentamos uma breve análise sobre como a Educação Ambiental está orientada na versão final da Base Nacional Comum Curricular (BNCC). Vale ressaltar que a proposição de uma Base Nacional Curricular é tida por diversos atores do cenário políticoeducacional brasileiro como passo fundamental em direção a garantia do direito a aprendizagem e a equidade educacional. Materializando-se, portanto, como documento norteador dos currículos tornando-se essencial à sua análise para a inserção da Educação Ambiental (EA) escolar diante das

Interfaces da Educ., Paranaíba, v.10, n.28, p.445 à 467, 2019 
mudanças que veemente ocorrerão para atender as demandas e orientações da BNCC.

Dessa forma, a escolha pelo tema se justifica pelas mudanças significativas no campo da Educação Ambiental nos últimos anos refletindo diretamente na BNCC e que se expressará nos Projetos Politicos Pedagógicos (PPP) e nos currículos a qual já estão em fase de construção, adaptação e efetivação para direcionar o campo educacional. Todavia teremos como consequência mudanças que afetarão os rumos da Educação Ambiental no Brasil, por isso se faz necessária uma análise crítica das políticas públicas educacionais contemporâneas relativas à EA, para a compreensão das mudanças no campo da Educação Ambiental e ainda para a proposição de um dialogo que detenha ou impeça a potencialização do mercado em detrimento dos impactos ambientais negativos ocasionados ao meio ambiente.

Vemos com indignação que os investimentos em direitos sociais são os mais duramente atacados e, nesse pacote, encontra-se a educação que, conforme a conveniência da situação é tratada ora como gasto, ora como investimento. Não raro, identificamos uma aproximação entre questões relativas à educação e à economia, que se concretiza de forma evidente no uso de palavras que apontam para o âmbito econômico (ADRIÃO et al., 2016)

Sobre isso, de um ponto de vista linguístico-discursivo, "as unidades lexicais tendem a adquirir o estatuto de signos de pertencimento. Entre vários termos a priori equivalentes, os enunciadores serão levados a utilizar aqueles que marcam sua posição no campo discursivo" (MAINGUENEAU, 2008, p. 81). Assim, termos como competitividade, competência, eficácia, eficiência, desempenho estão cada vez mais naturalizados não só nas instituições de ensino, mas, principalmente, em textos dos documentos que pautam a educação no Brasil, numa evidente mercantilização da educação.

E não é por acaso! Tal modo de ver a educação como mercadoria (BAUMAN, 2005) resulta de políticas que buscam uma redefinição do papel de um estado que reafirma seu valor democrático, ao mesmo tempo em que

Interfaces da Educ., Paranaíba, v.10, n.28, p.445 à 467, 2019 
desmantela esse mesmo estado em vistas de favorecer um mercado que visa à manutenção e expansão dos lucros.

Contrariando os interesses do mercado temos que o estado deve garantir conhecimento, mas também ferramentas e instrumentos para o uso ético, responsável e sustentável do conhecimento. Isso é, uma educação para a cidadania que abrange habilidades cognitivas e não cognitivas incluídas nelas as habilidades sociais como empatia, resolução de conflitos e interação sociocultural e ambiental, por exemplo. Essa educação - seja no âmbito formal ou não formal - visa formar cidadãs e cidadãos que assumam papeis ativos na construção de uma sociedade mais igualitária, justa, pacífica e sustentável.

Nesse sentido, este capítulo tem por objetivo analisar sob a perspectiva do método da complexidade qual o espaço dedicado a Educação Ambiental no currículo, uma vez que é exigido por lei a sua inserção, inclusive, na educação básica, e de que forma ela vem atravessando as contrarreformas da educação brasileira; nesta análise abordando e compreendendo a versão homologada da BNCC de Dezembro de 2018, compreendendo que a Educação Ambiental vem cada vez mais perdendo espaço nas disputas pela formulação do currículo da Educação básica.

\section{Revisão bibliográfica}

\section{O marco histórico da legislação da educação ambiental no brasil}

Iniciamos a pesquisa construindo nossa problemática, apresentando o marco histórico em documentos oficiais referentes à inserção da EA na Educação básica que ocorreram nas últimas décadas, serviram como arcabouço para a Legislação e Educação Ambiental. De acordo com Weyand et al., (2008), alguns documentos elaborados foram fundamentais para consolidação de Políticas Públicas na Educação Ambiental (BRASIL, 1981; 1988; 1996; 1999; 2002; 2012), o que nos permitiu compreender melhor as modificações nas concepções sobre seu ensino e de que forma, hoje, essa inserção é apresentada na BNCC.

Interfaces da Educ., Paranaíba, v.10, n.28, p.445 à 467, 2019 
Educação Ambiental: Retrocessos e contradições...

Destacamos alguns documentos oficiais promulgados no Brasil que tratam sobre a Educação Ambiental:

a) Lei Federal $n^{\circ} .6938$ de 1981, que estabelece a Politica Nacional do Meio Ambiente, na qual a Educação Ambiental é situada como um dos componentes que contribui na solução dos problemas ambientais, sendo ofertada a todos os niveis e modalidades de ensino;

b) Promulgação da Constituição Federal em 1988, que seu Art. 225, § $1^{\circ}$, inciso VI, determina que a Educação Ambiental juntamente com a promoção da conscientização social para defesa do meio ambiente é dever do Poder Público, indicando que as lutas de classe estavam refletindo nas decisões dos Constituintes;

c) Aprovação dos Pareceres $n^{\circ}$. 04/98 e o $n^{\circ}$. 15/98 do Conselho Nacional da Educação, que por sua vez, estabelecem as Diretrizes Curriculares Nacionais para o Ensino Fundamental e Médio;

d) Lei $n^{\circ}$. 9795/99/DOU institui a Política Nacional de Educação Ambiental e o Decreto $n^{\circ}$. 4281/02 regulamenta a referida Lei.

e) Aprovação da Resolução n. ${ }^{\circ} 02$ de 15 de junho de 2012, que estabelece as Diretrizes Curriculares Nacionais para a Educação Ambiental, reconhecendo a relevância e obrigatoriedade da Educação Ambiental em todos os niveis e modalidades de ensino.

$\mathrm{Na}$ BNCC, a Educação Ambiental é citada na introdução deste documento, na qual incumbe aos sistemas, às redes de ensino e às escolas, incluir a EA de forma transversal e integradora, conforme dispostos nos documentos anteriores apresentados sobre esta no Brasil. Na "BNCC, essas temáticas são contempladas em habilidades dos componentes curriculares, cabendo aos sistemas de ensino e escolas, de acordo com suas especificidades, tratá-las de forma contextualizada.” (BRASIL, 2018, p. 20).

Cabral (2008) destaca o caráter relativamente recente da legislação ambiental brasileira é de se reconhecer o relevante papel a ser desempenhado por essa educação na disseminação de conceitos e regras legais que sirvam à construção de valores, atitudes e condutas positivas ambientalmente, indispensáveis, portanto, ao disciplinamento da relação da

Interfaces da Educ., Paranaíba, v.10, n.28, p.445 à 467, 2019 
sociedade com o espaço natural ou construído. Nesse contexto a Educação Ambiental surge como política pública e torna-se indispensável apresentar a politica concernente ao tema relacionando as influências da legislação sobre a Educação.

\section{A Educação Ambiental frente á Base Nacional Comum Curricular (BNCC)}

A proposta de elaboração de um currículo nacional não é recente, é um processo histórico das construções e debates sobre as politicas educacionais, na direção de que a BNCC seja referência curricular em nivel nacional, com objetivo de estabelecer conteúdos mínimos para a Educação básica, unificando os currículos e Projetos Políticos Pedagógicos (PPP) nas escolas em todo Brasil. Essa iniciativa já era prevista na Constituição de 1988, na LDB (Lei nº 9394/96) e no Plano Nacional de Educação - PNE de 2014 (BRASIL, 2014).

Em consonância, com a Lei n 9.394/1996 (LDB), a Base Nacional Comum Curricular é um documento de caráter normativo, que tem como propósito estabelecer conhecimentos, competências e habilidades que devem ser desenvolvidas por todos/as os/as estudantes durante o ensino básico, resguardando as especificidades regionais. Ela também prevê que devem ser estabelecidas competências gerais e específicas para as diferentes áreas de conhecimento e respectivos componentes curriculares em conformidade com o que preceitua o Plano Nacional de Educação (PNE) (BRASIL, 2014, p. 7).

É preciso advertir que a BNCC em nivel nacional gera impactos em diferentes segmentos do campo educacional, a saber: na formação de professores, na elaboração dos materiais didáticos e nas avaliações educacionais entre outras. Acreditamos que tais impactos não são garantias de avanços na educação, ao contrário, demostram retrocesso histórico, bem como a centralização e a homogeneização do complexo processo educacional brasileiro. O que observamos é que "a experiência dos professores e os currículos em andamento são negligenciados na BNCC". "E a localidade, a diversidade, a negociação de sentidos, a autonomia da escola não aparecem no texto das BNCC" (GALIAZZI, 2018).

Interfaces da Educ., Paranaíba, v.10, n.28, p.445 à 467, 2019 
A falta de consenso sobre esses impactos no campo educacional e o verdadeiro papel da escola, pode repercutir na formação de cidadãos pouco críticos, deixando a sociedade à mercê das efemeridades das políticas públicas e interesses do mercado. Assim, é de se esperar que exista uma lacuna para a promoção de uma Educação Ambiental efetiva. Neste sentido, é indispensável o estudo sobre o currículo e o fortalecimento da área da Educação Ambiental mesmo que a sua presença na BNCC é conduzida pela omissão.

É importante destacar ainda que, de forma geral, o currículo na escola é organizado de acordo com a realidade social do aluno num ponto específico do tempo e do espaço. Sem desconsiderar um fator importante a ser considerado, há de se observar, também, um possível esvaziamento e desenvolvimento para o endurecimento de uma visão reducionista do professor com relação à Educação Ambiental pela desobrigação e isenção dada pela interpretação e relevância no currículo frente às versões anteriores da BNCC.

Apesar de décadas de disputas, o avanço da legislação brasileira no sentido de estimular a Educação Ambiental crítica e reflexiva, de forma a estabelecer relações entre os problemas socioambientais e o modo de organização político-econômico brasileiro, para além do desenvolvimento da consciência individual sobre atitudes cotidianas é inegável. Neste sentido, nos dedicaremos a seguir a análise partindo das referências na legislação vigente para compreender o processo de inserção ou ocultamento da Educação Ambiental na BNCC.

Para então compreender como a Educação Ambiental está disposta na versão homologada na BNCC, nos embasamos no seguinte problemática: "Quais são as referências a Educação Ambiental na Base Nacional Comum Curricular (BNCC) na versão homologada para a Educação básica?”.

\section{Metodologia}

Moraes e Galiazzi (2017) apresentam a Análise Textual Discursiva ATD como uma metodologia de análise de informação de natureza qualitativa

Interfaces da Educ., Paranaíba, v.10, n.28, p.445 à 467, 2019 
de característica exploratória para produzir novas compreensões sobre textos e discursos. A análise textual discursiva pode ser compreendida como um processo auto-organizado de construção de compreensão em que novos entendimentos emergem de uma sequência recursiva de três componentes: desconstrução do corpus, a unitarização e a categorização (MORAES, 2003).

Busca-se, com a ATD, o aprofundamento do pesquisador sobre o processo de desconstrução chamado de unitarização, processo recursivo de mergulho nos sentidos atribuídos aos textos em análise. Das unidades de significado, encaminha-se para o processo de organização de unidades com a elaboração de categorias iniciais, que, aproximadas, possibilitam a elaboração de categorias intermediárias e, em um novo esforço perceptivo, emergem no horizonte de compreensão do pesquisador categorias finais acerca do fenômeno.

A categorização se apresenta como processo de aprendizagem e comunicação de novos entendimentos em um movimento de síntese e construção de sistemas de categorias com as novas aprendizagens e compreensões que originam um metatexto (MORAES; GALIAZZI, 2016; SOUSA; GALIAZZI, 2017).

A Base Nacional Curricular Comum foi lida sistematicamente para iniciar o primeiro processo de análise que consiste na desconstrução dos textos com posterior unitarização. Com esta fragmentação surgiram as unidades de análise, sendo que cada uma dessas foram codificada para saber a origem de cada unidade.

Nessa metodologia de análise, primeiro se obtém as unidades de significado, a qual é organizada em três componentes para categorização que são: unitarização das informações obtidas, categorização dessas informações e produção de sínteses compreensivas.

Desse modo, nada se perde no registro das unidades de sentido, pois aquele item que apresenta um registro insistente detectado durante a análise das respostas é tão útil, como aquele que aparece uma única vez. Essa prospecção torna a ATD um método onde se percebe claramente tanto 
o que prevalece, como o que é pouco nítido, nas descrições documentais para a análise em questão.

O levantamento do corpus para a análise seguiu uma delimitação e seleção rigorosa (MORAES, 2003), com a busca feita na BNCC, utilizando os termos "Educação Ambiental” ou "Temática Ambiental” em toda a extensão do documento em que se buscaram sistematicamente pelos termos mencionados. Foi obtido apenas uma referência a "Educação Ambiental" e 32 referências a “Temática Ambiental”.

\section{RESULTADOS E DISCUSSÕES}

\section{Elementos de Educação Ambiental e Temática Ambiental na BNCC}

Inicialmente a palavra escolhida para busca foi "Educação Ambiental" e obtivemos apenas um resultado, assim optamos pela "temática ambiental", em que encontramos 32 referências à temática ambiental.

Aqui apresentamos no Quadro 01, o que encontramos em referência à “temática ambiental” na Base Nacional Comum Curricular (BNCC).

\section{Quadro 01: Palavras-chave encontradas relacionadas à temática ambiental}

\begin{tabular}{|l|c|}
\hline Temática “Ambiental” & $\begin{array}{c}\text { Número de vezes que cada palavra } \\
\text { aparece no contexto da BNCC }\end{array}$ \\
\hline$\checkmark$ Degradação ambiental & 1 \\
$\checkmark$ Equilíbrio ambiental & \\
$\checkmark$ Importância ambiental & 2 \\
$\checkmark$ Papel ambiental & \\
$\checkmark$ Extica socioambiental & 3 \\
\hline$\checkmark$ Diversidização ambiental ambiental & \\
$\checkmark$ Qualidade ambiental & 5 \\
\hline ambiental & 10 \\
\hline$\checkmark$ Socioambiental & \\
\hline Sustentabilidade & \\
\hline$\checkmark$ Conscioambiental & \\
\hline
\end{tabular}

Interfaces da Educ., Paranaíba, v.10, n.28, p.445 à 467, 2019 
Após a seleção do corpus de análise, foi realizada a leitura minuciosa, com olhar direcionado para o objeto de investigação e, posteriormente, a organização dos achados, a partir do destaque das unidades de análise, também denominadas unidades de significado (MORAES; GALIAZZI, 2016).

Para análise das unidades de significado recorremos aos três componentes utilizados na metodologia de Análise Textual Discursiva-ATD, que compreendem as etapas de: unitarização das informações obtidas, categorização dessas informações e produção de sínteses compreensivas (MORAES; GALIAZZI, 2016).

Ao destacarmos as unidades de significado, registramos a localização das mesmas, o que contribuiu significativamente para o movimento recursivo ao corpus de análise. No Quadro 02 apresentamos exemplos de unidades de significado da "temática ambiental" indicadas na BNCC.

Quadro 02: Unidades de significado: Temática Ambiental

\begin{tabular}{|c|c|}
\hline Localização & Exemplos de Unidade de Significado \\
\hline $\begin{array}{l}\text { Competências } \\
\text { gerais }\end{array}$ & $\begin{array}{l}\text { Argumentar com base em fatos, dados e informações } \\
\text { confiáveis, para formular, negociar e defender ideias, } \\
\text { pontos de vista e decisões comuns que respeitem e } \\
\text { promovam os direitos humanos, a consciência } \\
\text { socioambiental e o consumo responsável (p. 9). }\end{array}$ \\
\hline $\begin{array}{l}\text { Competências } \\
\text { especificas de } \\
\text { linguagens para o } \\
\text { ensino } \\
\text { fundamental }\end{array}$ & $\begin{array}{l}\text { Utilizar diferentes linguagens para defender pontos de } \\
\text { vista que } \\
\text { respeitem o outro e promovam os direitos humanos, a } \\
\text { consciência } \\
\text { socioambiental e o consumo responsável em âmbito } \\
\text { local, regional } \\
\text { e global, atuando criticamente frente a questões do } \\
\text { mundo } \\
\text { contemporâneo (p. 65). }\end{array}$ \\
\hline $\begin{array}{l}\text { Educação Física - } \\
8^{\circ} \\
\text { e } 9^{\circ} \text { ano / } \\
\text { Habilidades }\end{array}$ & $\begin{array}{l}\text { Experimentar e fruir diferentes práticas corporais de } \\
\text { aventura na natureza, valorizando a própria segurança e } \\
\text { integridade fisica, bem como as dos demais, respeitando } \\
\text { o patrimônio natural e minimizando os impactos de } \\
\text { degradação ambiental (p. 239). }\end{array}$ \\
\hline $\begin{array}{l}\text { Intervenção(Ciênc } \\
\text { ias da Natureza). }\end{array}$ & $\begin{array}{l}\text { Desenvolver ações de intervenção para melhorar a } \\
\text { qualidade de vida individual, coletiva e socioambiental } \\
\text { (p. 323). }\end{array}$ \\
\hline
\end{tabular}

Interfaces da Educ., Paranaíba, v.10, n.28, p.445 à 467, 2019 


\begin{tabular}{|c|c|}
\hline $\begin{array}{l}\text { Competências } \\
\text { especificas de } \\
\text { ciências da } \\
\text { natureza } \\
\text { para o ensino } \\
\text { fundamental }\end{array}$ & $\begin{array}{l}\text { Construir argumentos com base em dados, evidências e } \\
\text { informações } \\
\text { confiáveis e negociar e defender ideias e pontos de vista } \\
\text { que promovam a consciência socioambiental e o } \\
\text { respeito a si próprio e ao outro, acolhendo e valorizando } \\
\text { a diversidade de individuos e de grupos sociais, sem } \\
\text { preconceitos de qualquer natureza (p. 324). }\end{array}$ \\
\hline $\begin{array}{l}\text { Ciências }-4^{\circ} \text { ano } \\
\text { / Habilidades }\end{array}$ & $\begin{array}{l}\text { Relacionar a participação de fungos e bactérias no } \\
\text { processo de decomposição, reconhecendo a importância } \\
\text { ambiental desse processo (p. 339). }\end{array}$ \\
\hline $\begin{array}{l}\text { Ciências }-8^{\circ} \text { ano } \\
\text { / Habilidades }\end{array}$ & $\begin{array}{l}\text { Discutir iniciativas que contribuam para restabelecer o } \\
\text { equilibrio ambiental a partir da identificação de } \\
\text { alterações climáticas regionais e globais provocadas pela } \\
\text { intervenção humana (p. 349). }\end{array}$ \\
\hline $\begin{array}{l}\text { Competências } \\
\text { específicas de } \\
\text { ciências } \\
\text { humanas para } \\
\text { o ensino } \\
\text { fundamental }\end{array}$ & $\begin{array}{l}\text { Construir argumentos, com base nos conhecimentos } \\
\text { das Ciências Humanas, para negociar e defender ideias e } \\
\text { opiniões que respeitem e promovam os direitos humanos } \\
\text { e a consciência socioambiental, exercitando a } \\
\text { responsabilidade e o protagonismo voltados para o bem } \\
\text { comum e a construção de uma sociedade justa, } \\
\text { democrática e inclusiva (p. } 357 \text { ). }\end{array}$ \\
\hline $\begin{array}{l}\text { Competências } \\
\text { especificas de } \\
\text { geografia para o } \\
\text { ensino } \\
\text { fundamental. }\end{array}$ & $\begin{array}{l}\text { Construir argumentos com base em informações } \\
\text { geográficas, debater e defender ideias e pontos de vista } \\
\text { que respeitem e promovam a consciência } \\
\text { socioambiental e o respeito à biodiversidade e ao outro, } \\
\text { sem preconceitos de qualquer natureza (p. 366). }\end{array}$ \\
\hline $\begin{array}{l}\text { Objeto de } \\
\text { conhecimento } \\
\text { (Geografia }-5^{\circ} \\
\text { ano) }\end{array}$ & $\begin{array}{l}\text { Reconhecer e comparar atributos da qualidade } \\
\text { ambiental e algumas formas de poluição dos cursos de } \\
\text { água e dos oceanos (esgotos, efluentes industriais, marés } \\
\text { negras etc.) (p. 378). }\end{array}$ \\
\hline $\begin{array}{l}\text { Objeto de } \\
\text { conhecimento } \\
\text { (Geografia }-8^{\circ} \\
\text { ano) }\end{array}$ & $\begin{array}{l}\text { Diversidade ambiental e as transformações nas } \\
\text { paisagens na América Latina (p. 390). }\end{array}$ \\
\hline $\begin{array}{l}\text { Objeto de } \\
\text { conhecimento } \\
\text { (Geografia - } 9^{\circ} \\
\text { ano) }\end{array}$ & $\begin{array}{l}\text { Diversidade ambiental e as transformações } \\
\text { paisagens na Europa, na Ásia e na Oceania (p. 394). }\end{array}$ \\
\hline $\begin{array}{l}\text { Objeto de } \\
\text { conhecimento } \\
\text { (História - } 3^{\circ} \\
\text { ano). }\end{array}$ & $\begin{array}{l}\text { Identificar as diferenças entre o espaço doméstico, os } \\
\text { espaços públicos e as áreas de conservação ambiental, } \\
\text { compreendendo a importância dessa distinção (p. 410). }\end{array}$ \\
\hline $\begin{array}{l}\text { Linguagens e } \\
\text { suas tecnologias } \\
\text { no } \\
\text { ensino médio: } \\
\text { competências }\end{array}$ & $\begin{array}{l}\text { Formular propostas, intervir e tomar decisões que levem } \\
\text { em conta o bem comum e os Direitos Humanos, a } \\
\text { consciência socioambiental e o consumo responsável } \\
\text { em âmbito local, regional e global (p. 493). }\end{array}$ \\
\hline
\end{tabular}

Interfaces da Educ., Paranaíba, v.10, n.28, p.445 à 467, 2019 


\begin{tabular}{|c|c|}
\hline $\begin{array}{l}\text { específicas } \\
\text { e habilidades }\end{array}$ & \\
\hline $\begin{array}{l}\text { Ciências da } \\
\text { natureza e suas } \\
\text { tecnologias no } \\
\text { ensino médio: } \\
\text { competências } \\
\text { especificas e } \\
\text { habilidades }\end{array}$ & $\begin{array}{l}\text { Avaliar os riscos envolvidos em atividades cotidianas, } \\
\text { aplicando conhecimentos das Ciências da Natureza, para } \\
\text { justificar o uso de equipamentos e recursos, bem como } \\
\text { comportamentos de segurança, visando à integridade } \\
\text { fisica, individual e coletiva, e socioambiental, podendo } \\
\text { fazer uso de dispositivos e aplicativos digitais que } \\
\text { viabilizem a estruturação de simulações de tais riscos (p. } \\
559 \text { ). }\end{array}$ \\
\hline $\begin{array}{l}\text { Competências } \\
\text { especificas de } \\
\text { ciências } \\
\text { humanas e } \\
\text { sociais aplicadas } \\
\text { para o ensino } \\
\text { médio }\end{array}$ & $\begin{array}{l}\text { - Problematizar hábitos e práticas individuais e coletivos } \\
\text { de produção, reaproveitamento e descarte de residuos } \\
\text { em metrópoles, áreas urbanas e rurais, e comunidades } \\
\text { com diferentes características socioeconômicas, e } \\
\text { elaborar e/ou selecionar propostas de ação que } \\
\text { promovam a sustentabilidade socioambiental, o } \\
\text { combate à poluição sistêmica e o consumo responsável } \\
\text { (p. 575). } \\
\text { - Analisar os impactos socioambientais decorrentes de } \\
\text { práticas de instituições governamentais, de empresas e } \\
\text { de individuos, discutindo as origens dessas práticas, } \\
\text { selecionando, incorporando e promovendo aquelas que } \\
\text { favoreçam a consciência e a ética socioambiental e o } \\
\text { consumo responsável (p. } 575 \text { ). } \\
\text { - Contextualizar, comparar e avaliar os impactos de } \\
\text { diferentes modelos socioeconômicos no uso dos recursos } \\
\text { naturais e na promoção da sustentabilidade econômica e } \\
\text { socioambiental do planeta (como a adoção dos sistemas } \\
\text { da agrobiodiversidade e agroflorestal por diferentes } \\
\text { comunidades, entre outros). }\end{array}$ \\
\hline
\end{tabular}

No Quadro 02 agrupamos as unidades que se referem as doze palavras-chave que emergiram na busca, as quais aparecem na BNCC, mostrado anteriormente no Quadro 01. Desta agrupação buscamos analisar o destaque das demais unidades de significado das palavras-chave encontradas.

Assim categorizamos as unidades de significado, conforme apresentado no Quadro 03, para realizar a comparação entre as unidades definidas no momento inicial da análise, levando a agrupamentos de elementos semelhantes, como discutido por Moraes e Galiazzi (2016, p. 44). 
Educação Ambiental: Retrocessos e contradições...

O exercício de categorização configurou-se pelo agrupamento de duas categorias intituladas: Temática Ambiental e Socioambiental.

Quadro 03: Categorização das unidades de significado

\begin{tabular}{|c|c|c|}
\hline Categorias & 1- Temática Ambiental & 2 - Socioambiental \\
\hline Palavras-chave & $\begin{array}{ll}\checkmark & \text { Degradação } \\
& \text { ambiental } \\
\checkmark & \text { Equilibrio ambiental } \\
\checkmark & \text { Importância } \\
& \text { ambiental } \\
\checkmark & \text { Papel ambiental } \\
\checkmark & \text { Fiscalização } \\
& \text { ambiental } \\
\checkmark & \text { Diversidade } \\
& \text { ambiental } \\
\checkmark & \text { Qualidade ambiental } \\
\checkmark & \text { Conservação } \\
& \text { ambiental }\end{array}$ & $\begin{array}{l}\checkmark \text { Consciência socioambiental } \\
\checkmark \text { Sustentabilidade } \\
\text { socioambiental } \\
\checkmark \text { Socioambiental } \\
\checkmark \text { Ética socioambiental }\end{array}$ \\
\hline
\end{tabular}

Diante da organização da categorização de unidades de significado, desafiamo-nos a expressar nossas compreensões, constituídas com "argumentos centralizadores" (MORAES; GALIAZZI, 2016). Para tanto, na próxima seção apresentamos as sínteses compreensivas acerca das categorias emergentes.

\section{O panorama da Educação Ambiental na Base Nacional Comum Curricular}

Ao tratarmos a Educação Ambiental no contexto educacional brasileiro frente a Base Nacional Curricular Comum percebe-se uma forte disposição para aprovar e implantar políticas de cunho neoliberal e conservador que além de exaurir as posições de preservação e proteção do meio ambiente, vai na contramão dos objetivos da Educação Ambiental no currículo escolar visto que é um tema transversal, sendo assim de suma importância para a formação de cidadãos críticos e que se amplia para a economia, a justiça, a qualidade de vida, a cidadania e a igualdade.

Interfaces da Educ., Paranaíba, v.10, n.28, p.445 à 467, 2019 
Ao localizarmos a "Educação Ambiental" na BNCC chamou atenção por aparecer apenas uma única vez na introdução do documento. Nesse contexto, a Educação Ambiental é apresentada como mais um dos temas contemporâneos que devem ser incorporados aos currículos e às propostas pedagógicas das escolas, preferencialmente de forma transversal e integradora (BRASIL, 2018, p. 19).

No entanto ao considerar a EA vista em documentos anteriores a última versão homologada a EA é praticamente excluída da BNCC, o que nos causa estranhamento, posto que seja um campo de conhecimento em construção e crescimento (KAWASAKI e CARVALHO, 2009) e também de disputas e de conquistas, o qual vem se consolidando nas políticas públicas nacionais e internacionais (GUIMARÃES, 2018) que visam a sustentabilidade através de políticas públicas que compreendam os princípios de uma sociedade economicamente viável, socialmente justa, ecologicamente correto e culturalmente aceita.

Podemos compreender que o ocultamento da EA na BNCC seja produzido, especialmente, pelo papel político-pedagógico da Educação Ambiental, que possui caráter emancipatório e transformador e ao problematizar as relações sociais vigentes, atua no plano da existência, em que "o processo de conscientização se caracteriza pela ação com o conhecimento, pela capacidade de fazermos opções, por se ter compromisso com o outro e com a vida" (LOUREIRO, 2006, p. 28). A perspectiva transformadora da EA vai na contramão e com oposição à política neoliberal em expansão no país, que aposta no sucateamento da Educação, precarização do trabalho e na exploração do ser humano e dos recursos naturais.

Por entendermos a emergência da EA no contexto das escolas de Educação básica, respaldamos nosso entendimento na Lei n 9.795/99 que institui a Politica Nacional de Educação Ambiental-PNEA e indica que a EA é um componente essencial e permanente da educação nacional, devendo estar presente em todos os níveis da Educação Básica, assim como na Educação Superior, Educação Especial, Educação Profissional e na 
Educação de Jovens e Adultos. Na Educação escolar deve ser desenvolvida no âmbito dos currículos e das instituições de ensino público e privado como uma prática educativa integrada, continua e permanente em todos os niveis e modalidades do ensino formal (BRASIL, 1999).

Importa destacar o considerável avanço nas políticas públicas em se tratando do reconhecimento e da obrigatoriedade da Educação Ambiental na Educação Básica e no Ensino Superior, pois no ano de 2012, mediante a publicação da Resolução $n^{\circ} 2$, de 15 de junho de 2012, em conformidade com a $2^{\mathrm{a}}$ LDB (BRASIL, 1996) e com a PNEA (BRASIL, 1999), foram estabelecidas as Diretrizes Curriculares Nacionais para a Educação Ambiental-DCNEA.

Ao analisarmos as unidades de significado da categoria Temática Ambiental, elencamos para discussão as seguintes palavras-chave: "conservação ambiental", "diversidade ambiental” e "qualidade ambiental”. A análise das unidades de significados mostrou o predominio das correntes naturalista e conservacionista. A abordagem referente às correntes é apresentada na cartografia elaborada por Sauvé (2005, p. 17) como "uma maneira geral de conceber e de praticar a Educação Ambiental”.

A corrente naturalista é centrada na preservação e na relação com a natureza. A intenção central da EA é de reconstruir uma relação com a natureza. Na corrente conservacionista prevalecem características voltadas para a conservação dos recursos naturais, com enfoque cognitivo pragmático (SAUVÉ, 2005). Tristão (2008) pondera que a concepção naturalista traz consigo uma série de impactos negativos ao processo educacional, fazendo com que se corra o risco de perder a importância de uma análise social, econômica e política que envolve a abordagem da Educação Ambiental.

A corrente conservacionista se faz presente nas unidades de significado analisadas, estando relacionadas às áreas do conhecimento das Ciências da Natureza, da História e da Geografia. Percebe-se o destaque para as unidades temáticas em que o objeto do conhecimento e as habilidades a serem desenvolvidas direcionam-se para a identificação da diferença entre o espaço doméstico, os espaços públicos e as áreas de conservação ambiental.

Interfaces da Educ., Paranaíba, v.10, n.28, p.445 à 467, 2019 
As palavras-chave "diversidade ambiental" e a "qualidade ambiental" estão relacionadas com a corrente naturalista, pois ambas se destacam na unidade temática: "Natureza, ambientes e qualidade de vida" no ensino de Geografia. No contexto apresentado a diversidade ambiental como objeto de conhecimento representa a transformação das paisagens no ensino de Geografia, já a qualidade ambiental é destacada como objeto de conhecimento para reconhecer e comparar as caracteristicas da qualidade ambiental dos cursos de água e dos oceanos (esgotos, efluentes industriais, marés negras, etc.) (BRASIL, 2018).

Em vista disso a visão naturalista separa o ser humano do meio ambiente, colocando-o como mero observador, sem laços de pertencimento e responsabilidade se conduzindo pelo paradigma positivista e/ou pragmático. Nestes a EA é suspendida para ser estudada como objeto além do homem. Neste caso, a natureza é apreciada pela beleza cênica, demonstrando certa dose de religiosidade e romantismo e deve ser preservada por ser provedora de recursos sobre os quais temos o direito de uso. Essas representações parecem indicar distorções de caráter epistemológico na leitura do mundo (GUERRA; TAGLIEBER, 2002) e são coerentes com uma concepção fragmentada de aprendizagem. Nesse contexto, é indispensável romper com algumas amarras epistemológicas que têm por base a fragmentação entre o ser, o agir e o pensar.

Nessa mesma direção, a categoria socioambiental é apresentada na BNCC com uma visão mais ecológica, posto que as palavras-chave "socioambiental" e "sustentabilidade socioambiental" estão presentes na área das Ciências da Natureza no Ensino Fundamental e Ciências Humanas no Ensino Médio, sendo orientadas pelas unidades temáticas: Vida e evolução e Terra e universo. As unidades temáticas em que encontramos essas palavras destinam-se ao estudo de questões relacionadas aos seres vivos e as características de corpos celestes, o que nos mostra mais uma vez predomínio da corrente naturalista.

Podemos observar assim como Santinelo et al., (2016, p. 111) o predomínio da visão tradicional de EA "associado à ecologia, Interfaces da Educ., Paranaíba, v.10, n.28, p.445 à 467, 2019 
sustentabilidade, e muitas vezes deixando de lado seus aspectos social, ético, econômico, político, tecnológico e cultural, que devem capacitar ao pleno exercício da cidadania" ou ainda na visão de Guimarães (2018) esta não acrescenta mudanças paradigmáticas significativas às transformações necessárias à sociedade atual.

Nesse sentido em que mudanças vão interferir no currículo escolar a partir das mudanças na BNCC devemos desencorajar a abordagem da Educação Ambiental tradicional, uma vez que Loureiro (2004) nos alerta que a educação tida por tradicional, direciona o ato educativo para as mudanças de comportamento, compatíveis a um determinado padrão idealizado de relações corretas com a natureza, "reproduzindo o dualismo naturezacultura, com uma tendência a aceitar a ordem social estabelecida como condição dada, sem crítica às suas origens históricas" (LOUREIRO, 2004, p. 82).

Para ampliarmos o entendimento acerca da categoria em destaque, buscamos o esclarecimento sobre o termo socioambiental em que Loureiro (2014) afirma que a denominação está errada, pois se "o meio ambiente é uma sintese de relações sociais com a natureza em um determinado recorte espaço-temporal, o social é uma construção intrínseca” (LOUREIRO, 2014, p. 83). Porém ele afirma, ainda, que em certas situações, o termo é abordado para consolidar e demarcar o campo politico, considerando as relações sociais como fonte da crise ambiental.

Nessa perspectiva teórica, Carvalho (2012, p. 37) esclarece que a visão socioambiental pensa o meio ambiente como "um campo de interações entre a cultura, a sociedade e a base física e biológica dos processos vitais". Para a autora, nessa relação todos se modificam mutuamente, sendo que o meio ambiente é considerado como espaço relacional e a presença humana "aparece como um agente que pertence à teia de relações da vida social, natural e cultural e interage com ela" (CARVALHO, 2012, p. 37).

Seguidamente encontramos a palavra-chave "consciência socioambiental" nas seções referentes às competências gerais e específicas para o Ensino Fundamental nas áreas das Linguagens, das Ciências da Interfaces da Educ., Paranaíba, v.10, n.28, p.445 à 467, 2019 
Natureza, das Ciências Humanas e nas competências específicas na área de Linguagens do Ensino Médio. As unidades de significado mostram que os estudantes devem construir argumentos na defesa de posicionamentos que promovam a consciência socioambiental. E a palavra-chave "ética ambiental" como competência específica das Ciências Humanas e Sociais aplicadas para o Ensino Médio, no sentido de analisar os impactos socioambientais por práticas de instituições e assim favorecer a consciência em virtude as relações de consumo responsável.

Acreditamos que de forma implícita e intencional os conceitos relacionados à Educação Ambiental apresentada na BNCC reforçam as vertentes naturalista e conservacionista, orientada pela conscientização ecológica, pois tais vertentes "perdem de vista as dimensões sociais, politicas e culturais indissociáveis de sua gênese e dinâmica; e, contudo não incorporam as posições de classe e as diferentes responsabilidades dos atores sociais enredados na crise” (LAYRARGUES; LIMA, 2011, p. 7).

Além do silêncio sobre a Educação Ambiental, a "consciência socioambiental" foi à opção eleita para compor a BNCC, ainda que com raras citações. De acordo com Sorrentino e Portugal (2016), o termo "Educação Ambiental" é consolidado no Brasil, sendo mantido na literatura especializada, na legislação, nas escolas e nas comunidades. Os autores mostraram, no parecer sobre a primeira versão da BNCC, que o conceito mais coerente com a legislação e com a maior parte da produção científica é o de Educação Ambiental. O marco legal apresentado nesse estudo corrobora com essa afirmação, já que vemos um histórico de leis, decretos e portarias que se destinam à Educação Ambiental.

\section{Considerações finais}

Diante da constituição histórica da Educação Ambiental na Educação do Brasil, é possivel compreender que sua presença possibilita mudanças conceituais e atitudinais frente aos desafios e injustiças. Nesse contexto é preciso resistir para que a Educação Ambiental corrobore para a quebra de paradigmas na sociedade, capaz de contribuir para a formação de cidadãos

Interfaces da Educ., Paranaíba, v.10, n.28, p.445 à 467, 2019 
críticos, preocupados com a questão ambiental, aptos a decidir, agir e lutar frente às demandas que tratam a Educação Ambiental. Porém, é lamentável e um retrocesso para a educação no Brasil que a recente BNCC negligencie às políticas públicas que asseguram a presença da EA nas escolas.

Ao analisar os PCNs, as DCNs e a BNCC, documentos norteadores da Educação Básica, observa-se que há várias semelhanças entre os documentos anteriores e a versão homologada da BNCC quanto às considerações com relação à preservação do meio ambiente. Ainda assim, a versão final da BNCC para a Educação Básica nos diferentes níveis de ensino não menciona propriamente o termo Educação Ambiental. Em todos os documentos prevalece a Educação Ambiental como tema transversal, sobe o discurso de instigar a repensar novas práticas, e valorizar a relação do homem com a natureza, e discutir a sustentabilidade.

A análise das categorias emergentes mostrou que a Educação Ambiental perdeu espaço na BNCC. Deste modo, quando encontramos unidades de significados relacionadas a EA, verificamos o predomínio das vertentes naturalista e conservacionista. Além disso, as discussões acerca das questões socioambientais são apresentadas na BNCC na perspectiva ecológica, sem problematizar a EA enquanto um campo político que atua criticamente no equilibrio das relações de poder. Apesar disso a BNCC não apresenta nenhuma mudança significativa para o fortalecimento da Educação Ambiental no cenário da Educação nacional.

A análise mostrou também, que a EA na BNCC limita-se a específicos anos das áreas das Ciências da Natureza, Linguagens e da Geografia, a partir de conteúdos e conceitos que são organizados em unidades temáticas. Essa observação demostra a compartimentalização da EA, sendo apresentada reduzidamente de forma fragmentada, ao contrário do que assegura a legislação vigente. Diante do exposto acreditamos que a EA perdeu um importante espaço na disputa no currículo nacional para Educação básica, este fato nos parece intencional, na medida em que o ocultamento da EA propicia o silenciamento dos professores e dos estudantes.

Interfaces da Educ., Paranaíba, v.10, n.28, p.445 à 467, 2019 
$\mathrm{Na}$ contramão dessa intencionalidade, torna-se cada vez mais emergente consolidar nas escolas a Educação Ambiental na perspectiva crítica, emancipatória e transformadora, a qual busca a problematização das relações sociais e aposta no educar para emancipar e não alienar. Diante disso, é preciso resistir e potencializar os debates e a práxis em Educação Ambiental para se opor ao sistema que valoriza a mercantilização da educação. Como educadores devemos buscar educar para uma cidadania responsável, com consciência crítica, capacitando a agir e transformar o meio e a realidade na qual está inserido, superando os problemas, valorizando o indivíduo em detrimento do individualismo. Este sim é o compromisso dos profissionais da Educação de qualidade por meio da Educação Ambiental.

\section{Referências}

ADRIÃO, T. M. F. et al. Grupos empresariais na educação básica pública brasileira: limites à efetivação do direito à educação. Educação \& Sociedade, v. 37, n.134: 113-131, Campinas, 2016.

BAUMAN, Z. Los retos de educación en la modernidad líquida. Barcelona: Gedisa, 2005.

BRASIL. Base Nacional Comum Curricular (BNCC). Educação é a Base. Brasília, MEC/CONSED/UNDIME, 2018.

BRASIL. Lei n. 6.938, de 31 de agosto de 1981. Dispõe sobre a Política Nacional do Meio Ambiente, seus fins e mecanismos de formulação e aplicação, e dá outras providências. Brasília: 31 de ago. de 1981.

BRASIL. Constituição da República Federativa do Brasil de 1988. Promulgada em 05 de outubro de 1988.

BRASIL. Lei n. 9.394, de 20 de dezembro de 1996. Estabelece as diretrizes e bases da educação nacional.

BRASIL. Lei n. 9.795, de 27 de abril de 1999. Dispõe sobre a educação ambiental, institui a Politica Nacional de Educação Ambiental e dá outras providências. Brasília: 27 de abr. de 1999.

BRASIL. Ministério da Educação. Diretrizes Curriculares Nacionais para a Educação Ambiental. Brasília: Ministério da Educação /Conselho Nacional de Educação, 2012. 
BRASIL. Plano Nacional de Educação 2014-2024. Lei n ${ }^{\circ} 13.005$, de 25 de junho de 2014, que aprova o Plano Nacional de Educação (PNE) e dá outras providências. Brasília: Câmara dos Deputados, Edições Câmara, 2014.

CABRAL, L. O. Legislação Aplicada ao Meio Ambiente como Aporte à Educação Ambiental e Agenda 21 Escolar. In: PARANÁ. Cadernos Temáticos da Diversidade: Educação Ambiental. Secretaria de Estado da Educação. Curitiba: SEED, p. 64-78.

CARVALHO. I. C. M. Educação Ambiental: a formação do sujeito ecológico. 6. ed. São Paulo, Cortez, 2012.

GALIAZZI, M. C. (Des) necessária Base Nacional Curricular Comum - BNCC?. In: IV Congresso Internacional de Ensino das Ciências. Congresso online de pesquisa em Ensino de Ciências. 11 a 14 de jun, 2018.

GIL, A. C. Como elaborar projeto de pesquisa. 6. ed. São Paulo: Atlas, 2017.

GUIMARÃES, M. A Dimensão Ambiental na Educação. 12. ed. Campinas: Papirus, 2018.

GUERRA, A. F. S.; TAGLIEBER, J. E. A inserção da educação ambiental no currículo: o olhar dos pesquisadores de um programa de mestrado em educação. GE: Educação Ambiental, Itajaí, n. 22, 2002.

KAWASAKI, C. S.; CARVALHO, L. M. Tendências da pesquisa em Educação Ambiental. Educ. rev., Belo Horizonte, v. 25, n. 3, p. 143-157, Dec, 2009.

LAYRARGUES, P. P.; LIMA, G. F. C. Mapeando as macro-tendências políticopedagógicas da educação ambiental contemporânea no Brasil. In: Encontro de pesquisadores em Educação Ambiental, 6. Ribeirão Preto. Anais. Ribeirão Preto, 2011.

LOUREIRO, C. F. B. Trajetória e fundamentos da Educação Ambiental. São Paulo: Cortez, 2006.

LOUREIRO, C. F. B. Sustentabilidade e Educação: um olhar da ecologia política. São Paulo: Cortez, 2014.

LOUREIRO, C. F. B. Educação ambiental transformadora. In: BRASIL. Ministério do Meio Ambiente. Identidades da educação ambiental brasileira. Brasília, p. 65-84, 2004.

MAINGUEnEAU, D. Gênese dos discursos. São Paulo: Parábola, 2008.

MORAES, R.; GALliAZZI, M. C. Análise textual discursiva. 3. ed. Ijuí: Ed. Unijuí, 2016. 
SANTINELO, P. C. C.; ROYER, M. R.; ZANATTA, S. C. A Educação Ambiental no contexto preliminar da Base Nacional Comum Curricular. IN: Pedagogia em Foco, Iturama (MG), v. 11, n. 6, p.104-115, jul./dez, 2016.

SAUVÉ, L. Uma cartografia das correntes em Educação Ambiental. In: SATO, Michèle; CARVALHO, Isabel Cristina Moura (Orgs.). Educação Ambiental: pesquisas e desafios. Porto Alegre: Artmed, 2005.

SORRENTINO, M.; PORTUGAL, S. Educação Ambiental e a Base Nacional Comum Curricular. Parecer elaborado a pedido da Coordenação-Geral de Educação Ambiental do Ministério da Educação, 2016.

SOUSA, R. S.; GALIAZZI, M. C. O jogo da compreensão na análise textual discursiva em pesquisas na educação em ciências: revisitando quebracabeças e mosaicos. Ciênc. educ. (Bauru), Bauru, v. 24, n. 3, p. 799814, Sept, 2018.

SOUSA, R. S.; GALIAZZI, M. C. Compreensões acerca da Hermenêutica na Análise Textual Discursiva: Marcas Teórico-Metodológicas à Investigação. Revista Contexto \& Educação, v. 31, n. 100, p. 33-55, 2017.

TRISTÃO, M. A educação ambiental na formação de professores: redes de saberes. 2 ed. São Paulo: Annablume, 2008.

WEYAND, C. J.; JESUS, K. M.; LIOTTI, L. C., CARVALHO, P. M. Inserção da Educação Ambiental nos Currículos Escolares: O que Diz a Lei. In: PARANÁ. Cadernos Temáticos da Diversidade: Educação Ambiental. Secretaria de Estado da Educação. Curitiba: SEED, p. 79-90, 2008. 